\title{
HEALTH-RELATED QUALITY OF LIFE IN POORLY CONTROLLED TYPE 2 DIABETES PATIENTS - ASSOCIATION OF PATIENTS' CHARACTERISTICS WITH EQ-5D DOMAINS, MEAN EQ-5D SCORES, AND VISAUL ANALOG SCALE SCORE
}

\author{
MUBASHRA BUTT, ADLIAH MHD ALI*, MOHD MAKMOR BAKRY
}

Department of Quality use of medicine research group, Faculty of Pharmacy, Universiti Kebangsaan Malaysia, Jalan Raja Muda Abdul Aziz, Kuala Lumpur 50300, Malaysia. Email: adliah@ukm.edu.my

Received: 18 April 2017, Revised and Accepted: 29 September 2017

\section{ABSTRACT}

Objective: High prevalence of diabetes mellitus in Malaysia demands the appropriate interventions to alleviate or postpone its burden on patients' health-related quality of life (HRQoL). The studies which provide useful knowledge about the components of such interventions are important. The aim of this study was to describe how demographic and clinical characteristics of diabetes patients influence their HRQoL using EQ-5D.

Methods: This study used the baseline data of a randomized controlled study carried out to examine the impact of a pharmacist intervention on poorly controlled diabetes patients. A generic HRQoL tool EQ-5D was used to report the data. Logistic regression was used to identify the predictors of problems in individual EQ-5D domains, and ANCOVA was undertaken to examine the effect of patients' characteristic on EQ-5D mean scores and visual analog scale (VAS) mean scores.

Results: Pain discomfort was reported to be significantly predicted by high HbA1c levels. Increasing age (OR =1.04; CI 1.01, 1.16) and increasing body mass index $(\mathrm{OR}=1.15$; CI 1.01, 1.30) were significant predictors of reduced mobility. The presence of complications (OR $=8.03$; CI 1.34-48.02) and (5-10 years) diabetes duration predicted the reduced score in anxiety domain (OR = 7.05; CI 1.03, 48.04). Problems in usual activities were significantly predicted by age $(\mathrm{OR}=1.4 ; \mathrm{CI} 1.01,1.18)$. Self-care was not affected by any of the model covariates. Mean EQ-5D score was $(0.89$; CI 0.85 , $0.92)$ significantly predicted by HbA1c values ( $\mathrm{p}=0.04$ ). Mean VAS score (70.54) was significantly lower in the group receiving insulin (69.46; CI 73.74, 84.02) than the oral diabetes medication $(78.88$; CI 64.94, 73.98) ( $\mathrm{p}=0.009)$.

Conclusion: Patients' characteristics were significantly associated with the HRQoL in type 2 diabetes. There was a significant and inverse association of HRQoL with medication group (insulin use), high HbA1c, obesity, and presence of complications.

Keywords: Health-related quality of life, EQ-5D, Diabetes mellitus, Randomized controlled study.

(c) 2018 The Authors. Published by Innovare Academic Sciences Pvt Ltd. This is an open access article under the CC BY license (http://creativecommons. org/licenses/by/4. 0/) DOI: http://dx.doi.org/10.22159/ajpcr.2018.v11i1.19120

\section{INTRODUCTION}

Diabetes mellitus is a chronic medical condition which affects the people of all ages, races, regions, and economic statuses. The global prevalence of diabetes has reached the level of diabetes epidemic majorly due to population growth, aging, urbanization, and increasing prevalence of obesity and physical inactivity [1]. High prevalence of diabetes has attracted the researchers to investigate its complications and related effects on the life of patients. Health-related quality of life (HRQoL) is one such measure that helps in understanding the functional effects of a medical condition and/or its consequent therapy on a patient [2]. In this context, our study aimed to explore the HRQoL and its predicting factors in type 2 diabetes patients at a tertiary care hospital in Malaysia.

\section{Burden of diabetes in Malaysia}

The diabetes prevalence has been reported to increase at an alarming rate in Malaysia. The burden of diabetes in Malaysia was almost doubled to $22.9 \%$ in 2013 [3] compared to the $11.6 \%$ reported in 2006 [4]. If the World Health Organization (WHO) criteria for diabetes diagnosis was used, Malays showed the highest proportion with diabetes among the ethnic groups. However, when classification was based on the WHO criteria as well as an $\mathrm{HbA1c}>6.5 \%$, the Indians showed the highest proportion with diabetes (11.2\%) compared with the Malays (5.2\%) and Chinese (2.4\%) [3].

\section{Diabetes and HRQoL}

Diabetes has considerable potential to influence HRQoL due to its chronic and progressive nature. Previously, several studies have demonstrated the negative impact of diabetes' presence on patients' qualify of life. Significantly lower HRQoL was reported in people with diabetes than people without diabetes [5-8]. Progressive nature of diabetes is responsible for the development of related comorbidities such as foot ulcers, vision impairment, and nephropathy. The presence of such comorbidities impairs the quality of life in diabetes patients [9]. The burden of reduced HRQoL as a result of diabetes can take a toll on the performance of patients' routine functioning. A study reported that the average diabetes patients with lower quality of life were willing to trade away $12 \%$ of their remaining life in return for a diabetes-free health state [10].

Furthermore, the challenging task of managing diabetes involves constant adjustments and decision-making regarding the treatment; it predisposes the patients to increased psychological work. The findings of Scott et al. [11] support the notion of increased psychological pressure; the mental component of HRQoL in their study was significantly lower in patients with diabetes with poor glycemic control. Similar results were also reported in other studies $[12,13]$. Therefore, it becomes imperative to develop strategies and interventions that improve the quality of life in diabetes patients.

Clinical markers of diabetes such as HbA1c are frequently reported to indicate the disease control. However, holistic view of disease control and therapeutic outcomes can only be obtained by assessing the HRQoL in addition to the clinical markers. Studies which report patient characteristics and predictive factors of HRQoL facilitate the 
understanding of pertinent challenges experienced by diabetes patients. Identification of modifiable and associated predictive factors of the quality of life can facilitate the designing of appropriate interventions for improving the same. Most of the previous studies on HRQOL carried out in Malaysia report the status of HRQOL and/or analyzed the relationship of glycemic control with HRQoL among study participants [14-16]. Some studies have investigated the predictors of diabetes-specific HRQOL [17,18] and predictors of perception of diabetes-specific HRQoL across ethnic groups [19]. However, these studies used diseasespecific HRQoL instruments. One study used a generic instrument (SF-36) for the determination of HRQoL predictors [20]. The purpose of the present study was to assess the overall HRQoL and predictors of HRQoL in poorly controlled diabetes patients at a tertiary care facility using a generic HRQoL instrument EQ-5D. There have been concerns about the sensitivity of EQ-5D's capacity to capture the diabetes-related HRQoL. However, studies have shown that presence of subjective diabetes symptoms correlates significantly with EQ-5D scores, and therefore, adding a valuable dimension to the comprehensive HRQOL evaluations [21]. Regardless, the preference-based HRQoL instruments such as EQ-5D that evaluate health status are frequently used in diabetes research. The findings from such studies contribute toward resource allocations and related cost-utility analyses. Our study reported the EQ$5 \mathrm{D}$ results as a single summary index (mean scores) and investigated the association of EQ-5Dmean scores with patients' sociodemographic and diabetes-related clinical characteristics. There is a scarcity of studies from Malaysia which present the EQ-5D results of diabetes as a single summary index and explore the related predictive factors. The results of the present study may prove helpful in this regard.

Aim

The aim of this study was to investigate the HRQoL in diabetes patients using EQ-5D and investigate the association of patients' characteristics with EQ-5D mean scores/visual analog scale (VAS) scores and 5 domains of EQ-5D.

\section{METHODS}

The present study analyzed the baseline data of patients from a randomized controlled study [12] conducted at a tertiary care hospital in Malaysia. The study was approved by the University Kebangsaan Malaysia's Research Ethics Committee.

\section{EQ-5D}

EQ-5D is a preference-based HRQoL instrument which provides a generic, simple, and immediate measure of health situation for clinical and economic appraisal [22]. It consists of five domains of health (mobility, self-care, usual activities, pain, and anxiety) in the descriptive system and a VAS. For each domain, participants were asked to pick one of three levels to describe their current health state: Level $1=$ no problem, level 2 = some problem, and level 3 = extreme problem. The descriptive values were transformed into a single summary index using VAS valuation values provided by a Malaysian study [23]. VAS valuation values were preferred over the value sets derived from TTO valuation; the researchers found inconsistencies in the latter method and suggested value sets derived from VAS valuation would work better in the Malaysian setting [23].

\section{Data analysis}

Data were entered and analyzed using SPSS version 23. For descriptive analysis, sociodemographic and clinical data of participants were presented as a percentage, mean, and standard deviations. Age groups were based on the simple quartile distribution of the data. Body mass index (BMI) groups were based on the reference from the WHO [24]

The predictors of EQ-5D domains were investigated using binary logistic regression. Levels 2 and 3 of all 5 EQ-5D domains were merged to dichotomize the responses of participants into "level 1 = no problem" and "level 2 or 3 = some or extreme problem." Odds ratios with $95 \%$ confidence intervals were produced and interpreted; Chi-square values and Hosmer and Lemeshow statistics (H-L) were studied to report goodness of fit in the regression models. The covariates entered in the models were specified based on the inputs from diabetes educators and academic literature. The missing data for model covariates were imputed using multiple imputation commands in SPSS.

Analysis of variance and $t$-test were performed to analyze the mean difference in VAS and EQ-5D scores between subgroups of patients. Mean values of VAS and EQ-5D were adjusted by medication group and HbA1c values, respectively, using analysis of covariance (ANCOVA). Variable medication group was dummy coded and entered as a scalar covariate in ANCOVA. The assumption of homogeneity of regression slope was tested using SPSS; custom model of ANCOVA was run using interaction term of covariate and independent variable. Other statistical assumptions were checked and compiled before running all SPSS tests.

\section{RESULTS}

Data of total 73 patients were analyzed for predicting the determinants of EQ-5D domains and VAS scores. Among the participants, $41.1 \%$ were males and $58.9 \%$ females. Mean HbA1c value of the participants was $9.73 \% \pm 1.48$. Further descriptive statistics are shown in Table 1.

Out of total 73 patients, single summary index was obtained for 56 patients only. The limitation was imposed by the lack of relevant Malaysian value set for the health states reported in our study [23]. Therefore, the descriptive data for these 56 participants involved in EQ5D mean score analysis have been presented separately.

\section{EQ-5D domains}

Fig. $1 \mathrm{a}$ and $\mathrm{b}$ shows the percentage of patients reporting problems in five domains of EQ-5D descriptive system for 73 and 56 patients, respectively. In Fig. 1a, patients most frequently reported to encounter problems in domain of pain (40.3\%), followed by mobility (31.5\%) and

Table 1: Sociodemographic and clinical characteristics of the study participants

\begin{tabular}{|c|c|c|}
\hline Number of patients & 73 & 56 \\
\hline \multicolumn{3}{|l|}{ Age (years) } \\
\hline Mean \pm SD & $56.89 \pm 8.89$ & $56.62 \pm 7.73$ \\
\hline$>51$ & 23.3 & 21.4 \\
\hline $51-56$ & 27.4 & 28.6 \\
\hline $56-62.5$ & 23.3 & 26.8 \\
\hline$>62.5$ & 26.0 & 23.2 \\
\hline \multicolumn{3}{|l|}{ Gender } \\
\hline Female & 58.9 & 58.9 \\
\hline Male & 41.1 & 41.1 \\
\hline \multicolumn{3}{|l|}{ Presence of complications } \\
\hline Yes & 38.4 & 37.5 \\
\hline No & 61.6 & 62.5 \\
\hline \multicolumn{3}{|l|}{ Duration of diabetes (years) } \\
\hline$<5$ & 30.1 & 30.4 \\
\hline $5-10$ & 32.9 & 32.1 \\
\hline$>10$ & 37.0 & 37.5 \\
\hline \multicolumn{3}{|l|}{ Diabetes medication } \\
\hline Oral & 43.8 & 39.3 \\
\hline Oral + insulin & 56.2 & 60.7 \\
\hline \multicolumn{3}{|l|}{ Hba1 levels (percentage) } \\
\hline Mean \pm SD & $9.73 \pm 1.48$ & $9.64 \pm 1.58$ \\
\hline \multicolumn{3}{|l|}{ Ethnicity } \\
\hline Malay & 57.5 & 55.4 \\
\hline Indian & 23.3 & 23.2 \\
\hline Chinese & 19.2 & 21.4 \\
\hline \multicolumn{3}{|l|}{ BMI $\left(\mathrm{Kg} / \mathrm{m}^{2}\right)$} \\
\hline Mean $\pm S D$ & $28.83 \pm 4.81$ & $28.74 \pm 5.03$ \\
\hline Healthy (18.50-24.99) & 26.1 & 26.8 \\
\hline Pre obese (25.00-29.99) & 39.7 & 39.3 \\
\hline Obese $(\geq 30.00)$ & 34.2 & 33.9 \\
\hline
\end{tabular}


anxiety/depression (26.6\%) domain. For 56 patients, the percentage of patients reporting problems was $36.4 \%$ in pain/discomfort, $28.6 \%$ in mobility, $25.5 \%$ in anxiety/depression, $12.5 \%$ in usual activities, and $5.4 \%$ in self-care.

\section{Determinants of problems in EQ-5D domains}

Binary logistic regression analysis was carried out to predict the percentage of participants that reported problems in mobility using age gender, BMI, ethnicity, and presence of complications as predictors. Our $\mathrm{H}$-L statistics had a significance value of 0.17 which shows this model is a good fit. Overall prediction success for the model was $77.8 \%$. Age and BMI were significant predictors of reporting problems in mobility. None of the covariates in the model significantly affected the self-care. The presence of complications in participants significantly affected the reporting of problems in usual activities. Model showed the goodness of fit; HM stats value was 0.56 with $89 \%$ prediction success rate. Reporting problems in pain was significantly associated with $\mathrm{HbA1c}$ levels of the participants. HM statistics was 0.55 with overall prediction success of $63.9 \%$. The presence of complications and having diabetes for 5-10 years significantly determined the anxiety scores. HM statistics for goodness of fit was 0.86 with prediction success of $79.9 \%$. Results have been presented in Table 2 .

\section{EQ-5D scores and VAS scores}

The mean VAS score calculated from EQ-5D was 70.54. Medication group and $\mathrm{HbA1c}$ were found to be the significant predictors of mean
VAS scores. VAS scores of all the characteristics listed in Table 3 were adjusted by these two variables. EQ-5D scores were associated with HbA1c values at a significant level $(\mathrm{p}=0.04)$, and mean EQ-5D scores of the characteristics were adjusted accordingly. VAS score was significantly lower in participants receiving both OHA and insulin treatment (69.46; CI 73.74, 84.02) than participants of OHA group (78.88; CI 64.94, 73.98) ( $p=0.009)$. Unlike VAS scores, there was no difference in EQ-5D scores according to medication group. No differences in VAS scores were observed according to the presence or absence of diabetic complications. Mean EQ-5D score was slightly higher in the group with no diabetes complications $(0.88$; CI $0.82,0.94)$ than the group with diabetes complications $(0.89 ; \mathrm{CI} 0.84,0.94)$ ( $\mathrm{p}=0.7, \mathrm{~ns})$.

Participants with longer duration of diabetes reported highest VAS scores $(<5$ year $=72.21 ; 5-10$ years $=72.83$; more than 10 years = 75.39); however, the difference in scores with other groups was non-significant $(\mathrm{p}=0.71)$. Contrary to the VAS scores, highest EQ-5D scores were reported in the group with shortest duration of diabetes $(<5$ years $=0.93$, CI $0.86-0.99 ; 5-10$ years $=0.85$, CI 0.78, 0.92; $>10$ years $=0.88$, CI $0.82,0.94)(p=0.23)$. BMI values in the range of obesity were associated with low EQ-5D scores than the BMI values in the range of healthy weight and pre-obesity; however, the change was non-significant $(\mathrm{p}=0.38)$. For VAS scores, lowest VAS score was reported in participants with a healthy weight $(\mathrm{p}=0.17, \mathrm{~ns})$. There were no statistically significant differences in either VAS or EQ-5D scores

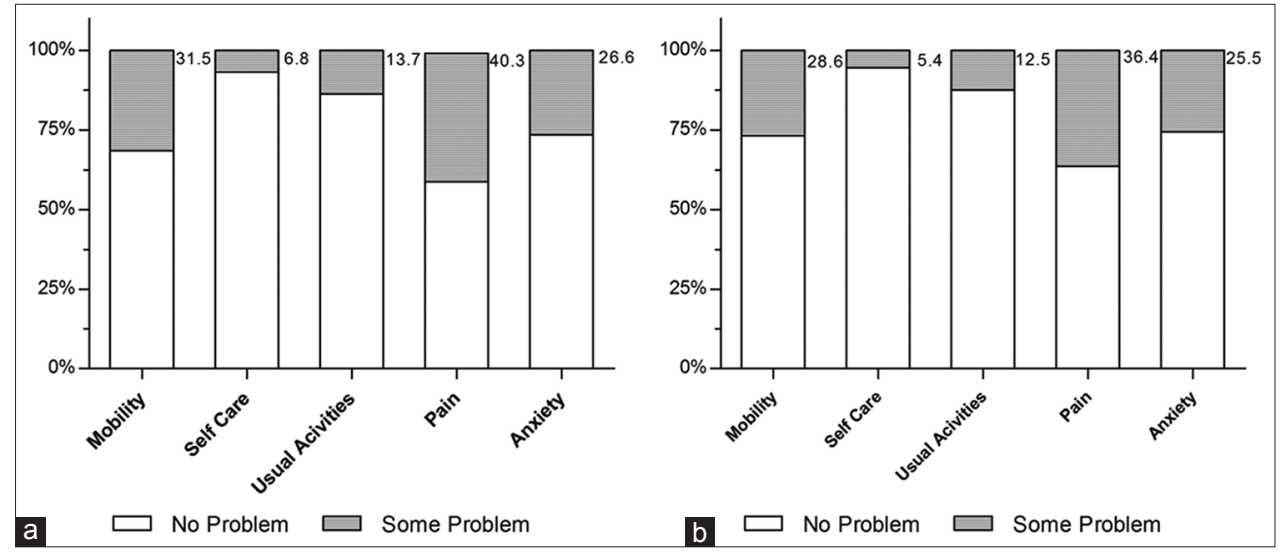

Fig. 1: Response to EQ-5D domains. (a), 73 patients, (b), 56 patients

Table 2: Patient characteristics and EQ-5D-3L domains (odds ratios, CI 95\%)

\begin{tabular}{|c|c|c|c|c|c|}
\hline Patient characteristics & Mobility & Self-care & Usual activities & Pain & Anxiety \\
\hline $\begin{array}{l}\text { Age (years) (per } 1 \text { year } \\
\text { increase) }\end{array}$ & $1.08(1.01-1.16)^{*}$ & $1.03(0.93-1.15)$ & $1.04(1.01-1.18)^{*}$ & $1.05(0.98-1.12)$ & $0.99(0.91-1.07)$ \\
\hline $\begin{array}{l}\text { Gender } \\
(\text { Female }=1 \text { male }=0)\end{array}$ & $1.19(0.37-3.85)$ & $0.45(0.07-3.17)$ & $1.18(0.22-6.33)$ & $0.92(0.33-2.56)$ & $1.58(0.40-6.31)$ \\
\hline $\begin{array}{l}\text { Presence of } \\
\text { complications }(\text { yes }=1, \text { no }=0)\end{array}$ & $2.75(0.77-9.76)$ & $2.74(0.34-21.95)$ & $12.31(1.61-91.36)^{*}$ & $1.49(0.41-5.39)$ & $8.03(1.34-48.02)^{*}$ \\
\hline $\begin{array}{l}\text { BMI }\left(\mathrm{Kg} / \mathrm{m}^{2}\right) \\
\text { (per } 1 \text { unit increase) } \\
\text { Ethnicity }\end{array}$ & $1.15(1.01-1.30)^{*}$ & $1.09(0.87-1.27)$ & $1.06(0.88-1.28)$ & - & - \\
\hline $\begin{array}{l}\text { Malay = } 1 \\
\text { Indian }=2\end{array}$ & $\begin{array}{l}2.58(0.468-14.166) \\
2.15(0.31-14.62)\end{array}$ & $\begin{array}{l}1.50(0.11-20.13) \\
1.04(0.05-21.99)\end{array}$ & $\begin{array}{l}0.32(0.038-2.75) \\
0.035(0.01-1.27)\end{array}$ & - & - \\
\hline $\begin{array}{l}\text { Chinese }=0 \\
\text { Medication }\end{array}$ & - & - & (1) & & \\
\hline $\begin{array}{l}(\mathrm{OHA}=1, \mathrm{OHA}+\text { insulin }=0) \\
\text { Duration of diabetes }(\text { years }) \\
<5=0\end{array}$ & - & - & - & $1.30(0.45-3.80)$ & $0.44(0.09-1.97)$ \\
\hline
\end{tabular}

*Means the values are statistically significant at $P<0.05$. Dotted line means variable was not included in the model 
Table 3: Patient characteristics and EQ-5D score, VAS score

\begin{tabular}{|c|c|c|c|c|c|c|}
\hline \multirow{3}{*}{$\begin{array}{l}\text { Patient } \\
\text { characteristics }\end{array}$} & \multicolumn{3}{|l|}{ VAS score $(n=73)$} & \multicolumn{3}{|c|}{ EQ-5D score $(n=56)$} \\
\hline & \multirow{2}{*}{$\begin{array}{l}\text { Mean } \\
73.70 \pm 15.12(\mathrm{SD})\end{array}$} & \multirow{2}{*}{$\begin{array}{l}\mathrm{C} 195 \% \\
70.15,77.26\end{array}$} & \multirow[t]{2}{*}{ p } & \multirow{2}{*}{$\begin{array}{l}\text { Mean } \pm S D \\
0.89 \pm 0.13\end{array}$} & \multirow{2}{*}{$\begin{array}{l}\text { CI 95\% } \\
0.85-0.92\end{array}$} & \multirow[t]{2}{*}{$\mathbf{p}$} \\
\hline & & & & & & \\
\hline \multicolumn{7}{|l|}{ Age groups } \\
\hline$>51$ & 69.31 & $62.35,76.26$ & 0.50 & 0.87 & $0.79,0.96$ & 0.98 \\
\hline $51-56$ & 76.27 & $69.87,82.67$ & & 0.90 & $0.82,0.97$ & \\
\hline $56-62.5$ & 74.79 & $67.77,81.81$ & & 0.89 & $0.82,0.97$ & \\
\hline \multicolumn{7}{|l|}{ Gender } \\
\hline Female & 73.10 & $68.71,77.48$ & 0.72 & 0.88 & $0.84,0.94$ & 0.99 \\
\hline Male & 74.30 & $69.04,79.57$ & & 0.88 & $0.83,0.95$ & \\
\hline \multicolumn{7}{|l|}{ Ethnicity } \\
\hline Malay & 74.76 & $70.33,79.17$ & 0.43 & 0.90 & $0.85,0.95$ & 0.60 \\
\hline Indian & 70.89 & $63.76,78.02$ & & 0.88 & $0.79,0.96$ & \\
\hline Chinese & 73.38 & $65.33,81.43$ & & 0.86 & $0.77,0.94$ & \\
\hline \multicolumn{7}{|c|}{ Duration of diabetes } \\
\hline $5-10$ & 72.83 & $66.96,78.70$ & & 0.85 & $0.78,0.92$ & \\
\hline$>10$ & 75.39 & $69.86,80.91$ & & 0.88 & $0.82,0.94$ & \\
\hline \multicolumn{7}{|c|}{ Diabetes medication } \\
\hline $\mathrm{OHA}$ & 78.88 & $73.74,84.02$ & $0.009 *$ & 0.088 & $0.82,0.94$ & 0.71 \\
\hline $\mathrm{OHA}+$ insulin & 69.46 & $64.94,73.98$ & & 0.89 & $0.84,0.94$ & \\
\hline \multicolumn{7}{|l|}{$\begin{array}{l}\text { Presence of } \\
\text { complications }\end{array}$} \\
\hline Yes & 73.64 & $68.22,79.05$ & 0.98 & 0.88 & $0.82,0.94$ & 0.77 \\
\hline No & 73.57 & $69.29,77.83$ & & 0.89 & $0.84,0.94$ & \\
\hline \multicolumn{7}{|l|}{ BMI } \\
\hline Normal & 68.15 & $61.52,74.76$ & 0.17 & 0.89 & $0.82,0.97$ & 0.38 \\
\hline Pre obese & 75.27 & $70.02,80.52$ & & 0.91 & $0.85,0.97$ & \\
\hline Obese & 75.78 & $70.10,81.46$ & & 0.85 & $0.79,0.92$ & \\
\hline \multicolumn{7}{|l|}{$\begin{array}{l}\text { Medication } \\
\text { adherence }\end{array}$} \\
\hline Non-adherent & 75.19 & $70.51,79.87$ & 0.33 & 0.90 & $0.85,0.95$ & 0.74 \\
\hline Med/adherent & 71.65 & $66.45,76.84$ & & 0.87 & $0.82,0.93$ & \\
\hline$>9-10$ & 74.95 & $68.49,81.39$ & & 0.90 & $0.83,0.97$ & \\
\hline$>10-11$ & 69.20 & $60.81,77.59$ & & 0.88 & $0.78,0.96$ & \\
\hline$>11$ & 74.07 & $61.57,86.59$ & & 0.70 & $0.56,0.83$ & \\
\hline
\end{tabular}

*Means values are statistically significant at $\mathrm{p}<0.05$. ANCOVA; VAS scores adjusted by age and medication group. EQ-5D scores adjusted by HbA1c. OHA: Oral hypoglycemic agents, BMI: Body mass index

according to age groups and gender.

\section{DISCUSSION}

This study analyzed the association of HRQoL with patient characteristics in diabetes patients. It tried to examine and identify the factors that predict the quality of life in type 2 diabetes patients. The identification of predictive factors and their association patterns prove helpful in selecting the appropriate interventions to improve HRQoL. Our study uses a generic HRQoL instrument to facilitate the understanding of predictive factors of poor quality of life in poorly controlled diabetes patients in a tertiary care center in Malaysia. Majority of participants $(57.7 \%)$ in our study were Malays, and this finding corresponds well with the distribution of the general population of Malaysia [3]. Diabetes patients reported to have a compromised HRQoL both by VAS scores and EQ-5D scores.

Among the five domains of health reported by EQ-5D, pain/discomfort was the domain where patients most frequently reported to encounter the problems. These results are consistent with the previous studies $[21,25]$. The presence of diabetes does not directly lead to pain; however, related complications and treatments such as peripheral neuropathies, delayed wound healing, and insulin injections can cause the pain and discomfort. Diabetic neuropathy is prevalent in diabetes and has been associated with the negative HRQoL [26]. More than half of the patients in our study were middle-aged or older; $38.4 \%$ of them had diabetes complications that can cause pain and discomfort. According to the results of regression analysis in our study, patients were 1.55 times more likely to report problems in pain/discomfort with an increase of each 1 unit in HbA1c $(1.55$; CI 1.02, 2.30) ( $p=0.043)$. Having higher HbA1c predisposes patients to the development of complications which in turn can lead to pain and discomfort. Pain is a significant determinant of poor quality of life, diabetes management interventions should not neglect this aspect, and concerted efforts should be made to alleviate its negative effects.

Next, domain most affected by diabetes in participants was mobility with $31.5 \%$ of patients reporting problems in this domain. Impaired mobility in diabetes is associated with decline in muscle power and neurophysiological functioning due to progressive nature of the disease and comorbidities $[27,28]$. Regression analysis in our study showed that increasing age and high BMI were significant predictors of problems in mobility. With each 1 unit increase in age, patients were 1.08 times more likely to report problems. Majority of our patients was middleaged or olderm thereby increasing the likelihood of the problems. $73.9 \%$ of participants had a higher BMI than a healthy weight range, with each 1 unit increase in BMI, the participants are 1.15 times more at risk of encountering problems in mobility. Our findings are close to the finding of the study by Solli et al. [9]; the odds of having mobility problems were increased 1.12 times with an increase in BMI. Age is a factor which cannot be modified however a better activity planning should be done to slow down the mobility impairment. With regard to 
BMI, the interventions for weight management should be undertaken by the patients to decrease the risk of mobility impairment.

Diabetes and depression/anxiety have been an active topic of interest for researchers. Previously, many studies have reported the negative impact of diabetes on the mental health of the patients $[11,25,29]$. Poor psychological well-being of the diabetes patients can stem from the constant worry about the progressive nature of the disease and development of complications. Consistent with a previous study [9], in our analysis, the presence of complications increased the likelihood of reporting problems in anxiety by $703 \%(\mathrm{OR}=8.03)$. The participants in our study had a poorly controlled HbA1c; hence, the risk of developing complications was higher. Duration of diabetes also significantly predicted the problems in anxiety. Patient with 5-10 years of duration were 7.08 times more likely to report problems in anxiety compared to $<5$ years duration. There are conflicting results about the association of depression with duration of diabetes. Previously, patients with similar duration of diabetes have been shown to have odds ratio of 1.92 for the occurrence of depression in diabetes patients compared to their non-diabetes counterparts [30]. However, the results of both studies cannot be compared precisely, and our study evaluated the poorly controlled diabetes patients while other study compared the odds of having problems in diabetes patients against non-diabetes population. In a study by Katon [31], the duration of diabetes longer than 5 years increased the risk of depression by $10 \%$ compared to the group having $<5$ years duration. Some studies have reported the lack of any significant association between diabetes duration and depression [32,33]. In our study, the increased risk of anxiety in 5-10 years duration may be explained by the stage of diabetes in these years. The complications of diabetes start developing with the progress of time; our study had poorly controlled patients with higher chances of complications development during this phase compared to a shorter duration. There was an increased likelihood (OR $=1.58, \mathrm{CI} 0.41,6.38$ ) of anxiety in female patients than the male patients; however, results were statistically non-significant.

A very small percentage of patients reported the problems in selfcare, and none of the covariates in the model significantly correlated with it. $13.7 \%$ of patients reported to have problems performing usual activities. Odds of having problems in usual activities increased 1.04 times with each unit increase in age. Furthermore, if patients were experiencing diabetes comorbidities, they were 12.31 times more likely to report problems in conducting usual activities than the group without comorbidities. These findings are comparable to the other studies that investigated the impact of diabetes complications on usual activities and overall quality of life [9,34]. Our study did not analyze the relationship of individual complication with usual activities; the studies which give a detailed analysis can contribute more effectively toward this topic. Nevertheless, diabetes complications that hinder the performance of usual activities in the patients should be addressed to improve their overall HRQoL.

Our study found no significant association between patient characteristics and VAS except for the medication group; therefore, values of the variables in the equation were adjusted by the medication group. Consistent with the previous findings [18,35], patients using insulin along with OHAs reported a lower VAS score (69.46) than the group using OHAs only (78.88) $(\mathrm{p}=0.009)$. Initiation of insulin therapy becomes essential in many patients at some stage of their disease; it cannot be excluded from their treatment. Therefore, the interventions and/or educational strategies should include the assessment of patients about their treatment modalities. If patients report negative perception of insulin on their HRQoL, their concerns should be addressed. The negative perception about the use of insulin could be potentially explained by the unpleasantness of procedure and a need for lifestyle modifications. There is mixed evidence in the literature regarding this association. Some studies have reported lack of any significant association between treatment modality and VAS scores in the studies conducted at other places using EQ-5D [21,36]. Unlike the VAS scores, EQ-5D scores showed no difference between OHA and OHA plus insulin group. Instead, the EQ-
5D score was slightly lower (0.87) in OHA group compared to the other group (0.89) ( $\mathrm{p}=0.17, \mathrm{~ns})$. These findings are in agreement with the previous literature $[21,22,36,37]$ that reported no significant association between HRQoL and treatment type using EQ-5D scores. Among the other substantial differences that were non-significant, patients with healthy weights reported a lower VAS scores than the pre-obese or obese patients; a higher VAS mean value was recorded in the non-adherent patients than the medium or adherent patients.

Patients reported a mean EQ-5D score of 0.89; EQ-5D scores were significantly determined by $\mathrm{HbA} 1 \mathrm{c}$ values in this study $(\mathrm{p}=0.04)$. Post hoc study of the HbA1c groups showed patients with HbA1c $>11$ had significantly lower EQ-5D values $(0.70)$ than the patients in the group with $\mathrm{HbA1c} 9-10(0.90)(\mathrm{p}=0.041)$. This finding is congruent with the previous studies which reported that higher HbA1c was associated with a lower EQ-5D score [25,35]. Having higher levels of HbA1c can contribute to the low HRQoL by either predisposing the patients to a higher risk of complications or imparting anxiety to them about the failure of glycemic control. Among other reasonable differences between groups that were non-significant, obese patients reported lower mean EQ-5D scores (0.85) than pre-obese (0.91) and healthy weight group (0.89); patients with diabetes duration $<5$ years reported higher HRQoL than the other groups with longer diabetes duration; and Malays had a higher score (0.90) than Indian (0.88) and Chinese (0.88) ethnic groups. In our study, although the difference among ethnicities did not reach statistical significance, the results were similar to a Malaysian study that reported highest HRQoL life scores for Malay, followed by Indians and Chinese [19].

\section{Limitations of the study}

This study had comparatively smaller sample size, and no sample calculations were performed. However, it can serve as preliminary/ pilot data about the similar studies at a bigger scale. It is important to interpret the results of the study with caution since the EQ-5D instrument is not diabetes-specific and compromised HRQoL scores may reflect the impact of unrelated comorbidity.

\section{CONCLUSION}

This study provides knowledge about the determinant of HRQoL in diabetes patients. Diabetes patients in this study frequently reported problems in pain/discomfort followed by anxiety/depression. Furthermore, it provides the HRQoL utility data for comparison of health states in diabetes patients across similar studies. Among modifiable factor, our study found a significant and inverse association of HRQoL with medication group (insulin use), high $\mathrm{HbA1c}$, obesity, and presence of complications. These results were supported by the existing literature. Therefore, it is reasonable to conclude that health-care interventions directed at preventing or adjusting insulin use, high HbA1c, obesity, and presence of complications will improve HRQoL indicators.

\section{REFERENCES}

1. Wild S, Roglic G, Green A, Sicree R, King H. Global prevalence of diabetes: Estimates for the year 2000 and projections for 2030. Diabetes Care 2004;27:1047-53

2. Fallowfield L. What is Quality of Life? 2009. Available from: http://www.medicine.ox.ac.uk/bandolier/painres/download/whatis/ WhatisQOL.pdf.

3. Wan Nazaimoon WM, Md Isa SH, Wan Mohamad WB, Khir AS, Kamaruddin NA, Kamarul IM, et al. Prevalence of diabetes in Malaysia and usefulness of $\mathrm{HbAlc}$ as a diagnostic criterion. Diabet Med 2013;30:825-8.

4. Letchuman GR, Wan Nazaimoon WM, Wan Mohamad WB, Chandran LR, Tee GH, Jamaiyah H, et al. Prevalence of diabetes in the Malaysian national health morbidity survey III 2006. Med J Malaysia 2010;65:180-6.

5. Kiadaliri AA, Najafi B, Mirmalek-Sani M. Quality of life in people with diabetes: A systematic review of studies in Iran. J Diabetes Metab Disord 2013;12:54.

6. Rubin RR, Peyrot M. Quality of life and diabetes. Diabetes Metabol Res Rev 1999;15:205-18. 
7. Sikdar KC, Wang PP, MacDonald D, Gadag VG. Diabetes and its impact on health-related quality of life: A life table analysis. Qual Life Res 2010;19:781-7.

8. Wee HL, Cheung YB, Li SC, Fong KY, Thumboo J. The impact of diabetes mellitus and other chronic medical conditions on healthrelated quality of life: Is the whole greater than the sum of its parts? Health Qual Life Outcomes 2005;3:2.

9. Solli O, Stavem K, Kristiansen IS. Health-related quality of life in diabetes: The associations of complications with EQ-5D scores. Health Qual Life Outcomes 2010;8:18.

10. Brown GC, Brown MM, Sharma S, Brown H, Gozum M, Denton P. Quality of life associated with diabetes mellitus in an adult population. J Diabetes Complications 2000;14:18-24.

11. Scott DM, Boyd ST, Stephan M, Augustine SC, Reardon TP. Outcomes of pharmacist-managed diabetes care services in a community health center. Am J Health Syst Pharm 2006;63:2116-22.

12. Butt M, Mhd Ali A, Bakry MM, Mustafa N. Impact of a pharmacist led diabetes mellitus intervention on $\mathrm{HbAlc}$, medication adherence and quality of life: A randomised controlled study. Saudi Pharm J 2016;24:40-8

13. Johnson CL, Nicholas A, Divine H, Perrier DG, Blumenschein K, Steinke DT. Outcomes from DiabetesCARE: A pharmacist-provided diabetes management service. J Am Pharm Assoc 2008;48:722-30.

14. Kamarul Imran M, Ismail AA, Naing L, Wan Mohamad WB. Type 2 diabetes mellitus patients with poor glycaemic control have lower quality of life scores as measured by the Short Form-36. Singapore Med J 2010;51:157-62.

15. Mafauzy M. Diabetes control and complications in public hospitals in Malaysia. Med J Malaysia 2006;61:477-83.

16. Lim PC,Lim K. Evaluation of a pharmacist-managed diabetes medication therapy adherence clinic. Pharm Pract (Granada)2010;8:250-4.

17. Chew BH, Mohd-Sidik S, Shariff-Ghazali S. Negative effects of diabetes-related distress on health-related quality of life: An evaluation among the adult patients with Type 2 diabetes mellitus in three primary healthcare clinics in Malaysia. Health Qual Life Outcomes 2015;13:187.

18. Daher AM, AlMashoor SA, Winn T. Glycaemic control and quality of life among ethnically diverse Malaysian diabetic patients. Qual Life Res 2015;24:951-8.

19. Goh SG, Rusli BN, Khalid BA. Diabetes quality of life perception in a multiethnic population. Qual Life Res 2015;24:1677-86.

20. Cheah W, Lee P, Lim P, Fatin Nabila A, Luk K, Nur Iwana A. Perception of quality of life among people with diabetes. Malays Fam Physician 2012;7:21-30

21. Sakamaki H, Ikeda S, Ikegami N, Uchigata Y, Iwamoto Y, Origasa H, et al. Measurement of HRQL using EQ-5D in patients with Type 2 diabetes mellitus in Japan. Value Health 2006;9:47-53.

22. Mehta Z, Cull C, Stratton I, Yudkin J. Quality of life in Type 2 diabetic patients is affected by complications but not by intensive policies to improve blood glucose or blood pressure control (UKPDS 37). Diabetes Care 1999;22:1125-36.

23. Yusof FA, Goh A, Azmi S. Estimating an EQ-5D value set for Malaysia using time trade-off and visual analogue scale methods. Value Health 2012;15 1 Suppl: S85-90.

24. WHO Expert Consultation. Appropriate body-mass index for Asian populations and its implications for policy and intervention strategies. Lancet 2004;363:157-63.

25. Shim YT, Lee J, Toh MP, Tang WE, Ko Y. Health-related quality of life and glycaemic control in patients with Type 2 diabetes mellitus in Singapore. Diabet Med 2012;29:e241-8.

26. Davies M, Brophy S, Williams R, Taylor A. The prevalence, severity, and impact of painful diabetic peripheral neuropathy in Type 2 diabetes. Diabetes Care 2006;29:1518-22.

27. Bruce DG, Davis WA, Davis TM. Longitudinal predictors of reduced mobility and physical disability in patients with Type 2 diabetes: The fremantle diabetes study. Diabetes Care 2005;28:2441-7.

28. Orr R, Raymond J, Singh MF. Efficacy of progressive resistance training on balance performance in older adults. Sports Med 2008;38:317-43.

29. Lau CY, Qureshi AK, Scott SG. Association between glycaemic control and quality of life in diabetes mellitus. J Postgrad Med 2004;50:189-93.

30. Almeida OP, McCaul K, Hankey GJ, Yeap BB, Golledge J, Norman PE, et al. Duration of diabetes and its association with depression in later life: The health in men study (HIMS). Maturitas 2016;86:3-9.

31. Katon WJ. The comorbidity of diabetes mellitus and depression. Am J Med 2008;121 11 Suppl 2:S8-15.

32. Raval A, Dhanaraj E, Bhansali A, Grover S, Tiwari P. Prevalence and determinants of depression in Type 2 diabetes patients in a tertiary care centre. Indian J Med Res 2010;132:195-200.

33. Thour A, Das S, Sehrawat T, Gupta Y. Depression among patients with diabetes mellitus in North India evaluated using patient health questionnaire-9. Indian J Endocrinol Metab 2015;19:252-5.

34. Lloyd A, Sawyer W, Hopkinson P. Impact of long-term complications on quality of life in patients with Type 2 diabetes not using insulin. Value Health 2001;4:392-400.

35. Redekop WK, Koopmanschap MA, Stolk RP, Rutten GE, Wolffenbuttel BH, Niessen LW. Health-related quality of life and treatment satisfaction in Dutch patients with Type 2 diabetes. Diabetes Care 2002;25:458-63.

36. Al-Aboudi IS, Hassali MA, Shafie AA, Hassan A, Alrasheedy AA. A cross-sectional assessment of health-related quality of life among Type 2 diabetes patients in Riyadh, Saudi Arabia. SAGE Open Med 2015;3:2050312115610129.

37. Javanbakht M, Abolhasani F, Mashayekhi A, Baradaran HR, Jahangiri Noudeh Y. Health related quality of life in patients with Type 2 diabetes mellitus in Iran: A national survey. PLoS One 2012;7:e44526. 